\title{
Determining generalizability of the Canadian Kidney Cancer information system (CKCis) to the entire Canadian kidney cancer population
}

Camilla Tajzler ${ }^{1}$; Simon Tanguay ${ }^{2}$; Ranjeeta Mallick ${ }^{3}$; Beau Ahrens ${ }^{4}$; Tina Luu Ly ${ }^{5}$; Rodney H. Breau $^{3}$; Naveen S. Basappa ${ }^{6}$; Anil Kapoor ${ }^{1}$; Daniel Y.C. Heng ${ }^{7}$; Frédéric Pouliot ${ }^{8}$; Antonio Finelli ${ }^{9}$; Luke T. Lavallée ${ }^{3}$; Alan I. So ${ }^{10}$; Darrel E. Drachenberg ${ }^{11}$; Denis Soulières ${ }^{12}$; Georg A. Bjarnason $^{13}$; Patrick O. Richard ${ }^{14}$; Ranjena Maloni ${ }^{9}$; Nicholas E. Power ${ }^{15}$; Michael Haan ${ }^{5}$; Lori A. Wood ${ }^{16}$

${ }^{1}$ Division of Urology, McMaster Institute of Urology, Hamilton, ON, Canada; ${ }^{2}$ Division of Urology, McGill University, Montreal, QC, Canada; ${ }^{3}$ Division of Urology, University of Ottawa, Ottawa, ON, Canada; ${ }^{4}$ Department of Graduate Studies, Dalhousie University, Halifax, NS, Canada; ${ }^{5}$ University of Western, Research Data Centre, London, ON, Canada; ${ }^{6}$ Department of Oncology, University of Alberta, Edmonton, AB, Canada; ${ }^{7}$ Tom Baker Cancer Centre, University of Calgary, Calgary, AB, Canada; ${ }^{8}$ Division of Urology, Department of Surgery, Université Laval, Quebec, QC, Canada; ${ }^{9}$ Division of Urology, University of Toronto, Toronto, ON, Canada; ${ }^{10}$ Department of Urologic Sciences, The University of British Columbia, Vancouver, BC, Canada; ${ }^{11}$ Section of Urology, University of Manitoba, Winnipeg, MB, Canada; ${ }^{12}$ Department of Medicine, University of Montreal Hospital Centre, Montreal, QC, Canada; ${ }^{13}$ Division of Medical Oncology/Hematology, Sunnybrook Odette Cancer Centre, University of Toronto, Toronto, ON, Canada; ${ }^{14}$ Division of Urology, University of Sherbrooke, Sherbrooke, QC, Canada; ${ }^{17}$ CKCis Project Manager; ${ }^{15}$ Division of Urology, Western University, London, ON, Canada;

${ }^{16}$ Department of Medicine and Urology, Dalhousie University, Halifax, NS, Canada

Acknowledgements: The CCR was accessed through a Statistics Canada Research Data Centre, thus we would like to acknowledge that "this research was supported by funds to the Canadian Research Data Centre Network (CRDCN) from the Social Sciences and Humanities Research Council (SSHRC), the Canadian Institute for Health Research (CIHR), the Canadian Foundation for Innovation (CFI), and Statistics Canada. Although the research and analysis are based on data from Statistics Canada, the opinions expressed do not represent the views of Statistics Canada."

Cite as: Can Urol Assoc J 2020 June 16; Epub ahead of print. http://dx.doi.org/10.5489/cuaj.6716

Published online June 16, 2020

$* * *$

Introduction: The Canadian Kidney Cancer information system (CKCis) has prospectively collected data on patients with renal tumors since January 1, 2011 from 16 sites within 14 academic centers in six provinces. Canadian kidney cancer experts have used CKCis data to address several research questions. The goal of this study was to determine if the CKCis cohort 
is representative of the entire Canadian kidney cancer population, specifically regarding demographic and geographic distributions.

Methods: The CKCis prospective cohort was analyzed up to December 31, 2018. Baseline demographics and tumor characteristics were analyzed including location of patients' residence at the time of CKCis entry. Geographic data is presented by province, rural versus urban via postal code info $\left(2^{\text {nd }}\right.$ digit $\left.=0\right)$ and by Canadian urban boundary files. To determine the proportion of renal cell carcinoma (RCC) patients that CKCis captures, CKCis accruals were compared to projected Canadian Cancer Society RCC incidence in 2016-2017 and the incidence from the 2016 Canadian Cancer Registry. To determine if the CKCis baseline data is representative, it was compared to registry data and other published data when registry data was not available.

Results: This CKCis cohort includes 10298 eligible patients: 66.6\% male, median age 62.6 years; $14.6 \%$ had metastatic disease at the time of diagnosis and $70.4 \%$ had clear-cell carcinomas. The CKCis cohort captures about 1250 patients per year, which represents approximately $20 \%$ of the total kidney cancer incidence. The proportion of patients captured per province did vary from $13-43 \%$. Rural patients make up $17 \%$ of patients, with some baseline differences between rural and urban patients. There appears to be no major differences between CKCis patient demographics and disease characteristics compared to national data sources. Canadian heat maps detailing patient location are presented.

Conclusions: CKCis contains prospective data on >10 000 Canadian kidney cancer patients making it a valuable resource for kidney cancer research. The baseline demographic and geographic data do appear to include a broad cross-section of patients and seem to be highly representative of the Canadian kidney cancer population. Moving forward, future projects will include determining if $\mathrm{CKC}$ is cancer outcomes are also representative of the entire Canadian kidney cancer population and studying variations across provinces and within rural vs. urban areas.

\section{Introduction}

The Canadian Kidney Cancer information system (CKCis) is a prospective national kidney cancer database that was initiated by Canadian kidney cancer clinicians and researchers in 2009. It was rolled out nationally and the system continues to prospectively collect de-identifiable data on patients with findings consistent with kidney cancer from January 1, 2011 onwards. CKCis is a source of data supporting many kidney cancer research initiatives and is used by many Canadian kidney cancer experts. Currently, data from patients with kidney tumors are collected from 16 sites within 14 academic centers (Supplementary Table 1) from 6 provinces. 
A potential concern with $\mathrm{CKCis}$ is whether the patients included, and data obtained from these sources, are generalizable to the entire Canadian population. Therefore, the objective of this study was to evaluate and analyze the CKCis kidney cancer patient population to determine if it is generalizable to the Canadian kidney cancer population. We report basic demographic data from CKCis including age at diagnosis, sex, ethnicity, histology, and proportion who present with de novo metastatic disease. We compare those statistics to available Canadian data from the 2016 Canadian Cancer Registry (CCR) and the 2015-2017 Canadian Cancer Society (CCS) as well as non-Canadian sources where no Canadian data exists. Additionally, we present the geographic distribution of CKCis patients at the time of CKCis entry across provinces and by rural versus urban location. This study includes CKCis patients with a malignant renal cancer or radiological/clinical features of malignancy but no pathological diagnosis as shown in the Consort Diagram in Figure 1.

\section{Methods}

All CKCis participating centers have obtained the appropriate local ethics board approval to include de-identified patient information. For this project, the cohort was restricted to all kidney cancer patients, both localized and metastatic, diagnosed from January 1, 2011 to December 31, 2018. Baseline demographics obtained include sex, age, ethnicity (as self-identified by patient), province at diagnosis, postal code at time of entry into CKCis, pathology, and stage (localized or metastatic). De novo metastatic disease was defined as metastatic disease found before or within 3 months of a kidney cancer diagnosis. Geographic data will be presented by province, rural versus urban via postal code information ( $2^{\text {nd }}$ digit $=0$ represents rural) and by the Forward Sortation Area boundary (FSA), which are based on Canadian postal codes. Geographic prevalence maps were created using ESRI ArcPro software.

To compare CKCis baseline demographic data with Canadian data, we utilized 1) 2016 CCR data for sex, median age, rural residence (by postal code) and pathology, and 2) 2016 Canadian Census data for race. In CKCis, patients self-identify as one race which includes Caucasian. Caucasian is not an option in the Canadian Census, however, we can discern whether a participant identifies as a visible minority through the Census. Visible minority is defined by the Employment Equity Act as "persons, other than Aboriginal peoples, who are non-Caucasian in race or non-white in colour". Thus, for the purpose of this project, anyone who did not identify as a visible minority was considered Caucasian. ${ }^{1}$

To determine the number of kidney cancer patients entered into CKCis (the numerator) as a proportion of all patients diagnosed with kidney cancer in Canada (the denominator), Canadian data was obtained from 1) the CCR for the most recent year available (2016) and 2) the most recent CCS estimated yearly incidence data (2015-2017). ${ }^{2-4}$ These data will be presented for all 
of Canada and by province. It is recognized that these administrative databases have limitations however, they are the only source of national data.

The CCR is a census of people diagnosed with cancer in Canada. It contains administrative information on cancer incidences, and individual and tumour characteristics from provincial and territorial cancer registries. ${ }^{5}$ The data were available from all provinces except for Quebec. Analyses using the CCR focused on individuals diagnosed with renal cell carcinoma (tumour topography coded as C64 in the ICD-O-3). Clear cell adenocarcinoma was determined by tumour histology (coded as 8310 in the ICD-O-3). To protect respondents' confidentiality, statistics are only released if based on 5 of more individuals and are rounded to a base of 5 . Provinces were aggregated when a cell of the table did not meet this minimum.

All eligible patients in the CKCis cohort were analyzed. For the comparison with 2016 CCR data, we utilized the 2016 CKCis cohort. Some CKCis sites do manage and enter data for patients who do not reside in their province (e.g. patients from Saskatchewan managed in Alberta). Therefore, for province specific information, only patients who resided in the 6 participating provinces at the time of their diagnosis were analyzed.

\section{Statistical analysis}

Patients who enrolled in CKCis with a primary or metastatic diagnosis between January 1, 2011 and December 31, 2018 were included. Percentages are used to summarize categorical variables. Age is summarized using the median and range. Chi-square tests were used when comparing the percentage of males and rural residency from the CKCis data with the CCR data. All the statistical analyses were performed using SAS 9.4 by SAS Institute Inc., Cary, NC, USA.

\section{Results}

\section{Baseline patient characteristics}

Figure 1 depicts the prospective CKCis cohort. Patients with non-kidney tumors were excluded $(n=152)$ as well as those with benign renal pathology, which include oncocytomas, benign mesenchymal tumors like angiomyolipomas, mixed epithelial and stromal tumors, and multilocular cystic renal neoplasms of low malignant potential $(n=566)$. The eligible CKCis cohort for this project includes 10,298 patients. Sixty-five $(0.6 \%)$ patients are from outside of the participating provinces.

Baseline demographics for the entire cohort are shown in Table 1 as well as by province. In the entire cohort, the median age was 62.6 years and the range was 61.4 years $(\mathrm{AB})$ to 64.4 years (NS). The range of ages was 19 to 96 years. Male patients made up $66.6 \%$ of the cohort and Caucasians made up $85.6 \%$. 


\section{Baseline disease characteristics}

A wide variety of malignant histologies are captured in CKCis as well as $15.4 \%$ of patients with no pathological diagnosis. The reasons for no pathology varies but include small renal masses on active surveillance, or tumors in patients too ill for a biopsy or for whom a biopsy would not appear to change management. Amongst all patients, 59.6\% have clear cell caracinoma. Amongst those with pathology, clear cell histology was seen in $70.4 \%$ of patients. Of the non clear cell cancers, papillary and chromophobe made up the majority at $13.5 \%$ and $6.6 \%$, respectively. Nephrectomy or partial nephrectomy specimens were used to make the diagnosis in $86.0 \%$ of patients, biopsy or fine needle aspirate in $13.6 \%$, and metastectomy in $0.5 \%$.

De novo metastatic disease was seen in $14.6 \%$ of patients and metastatic disease at any time was seen in $31.1 \%$.

\section{Geographic distribution of patients}

The number of CKCis patients per province is shown in Table 1. Geographic distribution of accrued prevalence rates for Canada by FSA are shown in Figure 2 for the entire country and by province/region. The areas with the highest concentration correspond to CKCis sites especially in Southern Ontario, the Ottawa region, Montreal and mainland Nova Scotia. However, the figures also show that patients are accrued from areas throughout the entire participating provinces.

The proportion of patients who live in a rural location is $17.0 \%$ with variation across the provinces ranging from $9.7 \%(\mathrm{BC})$ to $32.0 \%$ (NS). To note, rural and urban populations do show some differences in terms of baseline demographics. The mean age at presentation, percentage of males, and proportion of patients presenting with de novo metastatic disease are not statistically different. However, more patients with rural postal codes are Caucasian $(90.9 \%$ vs. $84.6 \%$, $\mathrm{p}<0.0001)$, have metastatic disease at any time $(33.1 \%$ vs. $30.7 \%, \mathrm{p}=0.04)$, and have clear cell pathology $(63.6 \%$ vs. $58.7 \%, \mathrm{p}<0.0001)$.

\section{CKCis baseline data compared to Canadian kidney cancer population}

Table 2 compares the baseline 2016 CKCis data with that of the entire Canadian kidney cancer population from the 2016 CCR for age, sex, rural residence, along with the proportion who present with de novo metastatic disease and clear cell pathology. There was no statistically significant difference between the CKCis data and the CCR concerning male population, rural residence, and clear cell pathology.

\section{Proportion of patients entered into CKCis compared to entire Canadian RCC population}

Table 3 reports CKCis Canadian and provincial accrual data along with CCS estimated incidence data, and CCR incidence data from 2016. In 2016, CKCis captured 20.7\% of the Canadian kidney cancer population (excluding data from Quebec) when compared to the CCR, and 19.6\% 
of the population (including Quebec) when compared to the CCS. The provinces varied from a low of $12.7 \%$ accrual (BC) to a high of $51.4 \%$ (NS). Table 3 also shows the differences between the CCS estimated incidence and the actual incidence data obtained from the CCR with notable differences in some provinces. Overall, the CCS estimated incidences are higher than the incidence data obtained from CCR with the exception of BC.

The CKCis accrual rate compared to CCS data in 2015 was $21.2 \%$ and in 2017 was $18.7 \%$. Provincial accrual rates again varied from $15.3 \%$ to $40.4 \%$. This data is shown in Supplementary Table 2.

\section{Discussion}

The publication and utilization of real-world data and evidence has become an integral part of research in oncology. Real world data may come from many different sources including individual institutions, specific regions, collaborations between investigators/clinicians or at national and international levels.

$\mathrm{CKCis,}$ as a multi-provincial source of real-world information, is an invaluable resource for clinicians, researchers, patients, and administrators to discover new information about the epidemiology, management, outcomes, and trends over time and across the country for the Canadian kidney cancer population. The data, however, are gathered from select Canadian academic centers, thus, it is important to understand if patients are representative of the entire Canadian kidney cancer population. Our hypothesis was that patients in CKCis represent the RCC population from many parts of the country with baseline patient and tumor characteristics similar to the entire kidney cancer population. CKCis results were compared to estimates published by the Canadian Cancer Society and actual data obtained from the Canadian Cancer Registry.

This study supports our hypothesis that the CKCis population is similar to the entire kidney cancer population of Canada in terms of baseline demographic and tumor characteristics. The median age at the time of diagnosis in CKCis (63 years) appears similar to the CCR (64 years). This is also in line with the US SEER database from 2012-2016 which reports a median age of 64 years at the time of diagnosis. ${ }^{6}$ Males make up $66.6 \%$ of the CKCis population $(65.5 \%$ in 2016), which is similar to the CCR at $64.9 \%$, and the CCS, which ranges between $62.9 \%$ and $65.3 \%$ from 2015 and $2019 .^{7}$

In terms of race, $\mathrm{CKCis}$ contains $86 \%$ of patients who self-identify as Caucasian. In the 2016 Canadian Census, $22 \%$ of the population identified as a visible minority and thus the assumption for this study is that $78 \%$ of the Canadian population was Caucasian in $2016 .{ }^{8}$ Thus, CKCis may have an over-representation of Caucasians. To note, the "visible minority" definition does not include Aboriginal Peoples and depending on how these patients self-identify, they 
would be included in the non-Caucasian category of CKCis but not the Canadian Census. In a previous publication from CKCis, $2.3 \%$ of patients self-identified as Indigenous. ${ }^{19}$

In $\mathrm{CKCis,} 70 \%$ of patients had clear cell RCC when analyzing only patients who had a histological diagnosis. This is similar to the often-reported $75-85 \%$ in the international literature. ${ }^{10}$ In $\mathrm{CKCis,} 59 \%$ of patients had clear cell RCC when including patients with and without pathology, which is almost identical to that seen in the CCR data. The reason for the lower proportion of clear cell RCC in the CCR and CKCis data is likely due to the inclusion of kidney cancers that are included based only on radiological imaging. Patients can be entered into provincial and territorial cancer registries and coded as kidney cancer with no pathology if the radiological findings are in keeping with kidney cancer. If the diagnosis is made radiologically, the pathology is usually entered as "Malignant Neoplasm" or "Renal Cell Carcinoma, NOS" which would be considered non clear cell and thus give a higher proportion of non clear cell RCCs. Research conducted with Nova Scotia provincial registry data found $11 \%$ of patients were diagnosed radiologically (and therefore would all be considered non clear cell). In that study, there was also up to $15.4 \%$ discordance between the NS Registry data and the diagnosis from actual pathology reports. ${ }^{11}$

De novo metastatic disease was diagnosed in $15 \%$ of patients in CKCis. Comparable data is not available from the CCR or any other Canadian source. The US SEER data from 2009-2015 reports $16 \%$ of patients are diagnosed with de novo metastatic disease. ${ }^{6}$ There was considerable variation in this variable across the country from $9.4 \%(\mathrm{QC})$ to $19.9 \%$ (BC) which will need further exploration.

The geographic inclusion of the CKCis population is vast and from all parts of the participating 6 provinces with a small number from surrounding provinces and territories. Given CKCis centers are in larger cities, we were concerned that rural patients may be underrepresented; however, rural patients make up $17.0 \%$ of the CKCis population, which is not significantly different than the CCR at $18.7 \%$. Statistics Canada indicates $18.9 \%$ of Canadians in 2011 lived in rural areas. ${ }^{12}$ Limitations to the geography data include the recording of the patient's postal code at the time of their first contact with a CKCis site and may not consider moves pre and post.

In terms of the proportion of kidney cancer patients that $\mathrm{CKCis}$ represents, CKCis captured about $20 \%$ of the Canadian kidney cancer population. It is difficult to know what proportion of patients are treated within the participating centers and simply not accrued into CKCis versus the proportion of patients managed outside of CKCis participating centers. The accrual of patients within CKCis does vary by site and province for many reasons but a major reason is the variation in consent processes across the country and even within provinces. For example, some centers have a waiver of consent and it is likely the vast majority of patients seen at that center are captured. Other centers have the option of telephone consents or waiver of 
consent for deceased patients. Some centers require all patients to sign an in-person consent form, which would result in a lower accrual rate. Now that we have seen the regional and provincial variations, it will allow the $\mathrm{CKCis}$ administrators and individual sites to strategize on how to maximize accrual at their site. These data also allow CKCis to monitor their success so that with each additional year the capture rate should improve. A very realistic goal is for CKCis is to capture data on 1 in 4 or $25 \%$ of kidney cancer patients.

\section{Conclusions}

Kidney cancer care is delivered in all regions and multiple centers across Canada. Due to logistics and resource constraints, not every patient with kidney cancer can be entered in CKCis. However, the key with a national database that cannot collect data on every individual kidney cancer patient is that it should still represent the entire population under study. The conclusion from this study is that the CKCis population has similar baseline patient and tumor characteristics to the general Canadian kidney cancer population and does not appear to be biased despite coming from academic centers only. These data suggest that research published using CKCis data are representative and generalizable to the Canadian population. This study has provided a benchmark for patient accrual that we can use to monitor new strategies and improvements in CKCis infrastructure. It has also raised a number of future research questions such as determining if CKCis cancer outcomes are also representative of the entire Canadian kidney cancer population and studying variations across provinces and within rural versus urban areas. 


\section{References}

1. Statistics Canada, Dictionary, Census of Population, 2016. Available at: https://www12.statcan.gc.ca/census-recensement/2-16/ref/dict/pop127-eng.cfm. Accessed March 6, 2020.

2. Canadian Cancer Society's Advisory Committee on Cancer Statistics. Canadian Cancer Statistics 2015. Available at: https://www.cancer.ca/ /media/cancer.ca/CW/cancer\%20information/cancer\%20101/Can adian\%20cancer\%20statistics/Canadian-Cancer-Statistics-2015-EN.pdf. Accessed Jan. 2, 2020.

3. Canadian Cancer Society's Advisory Committee on Cancer Statistics. Canadian Cancer Statistics 2016. Available at: https://www.cancer.ca/ /media/cancer.ca/CW/cancer\%20information/cancer\%20101/Can adian\%20cancer\%20statistics/Canadian-Cancer-Statistics-2016-EN.pdf. Accessed Jan. 2, 2020.

4. Canadian Cancer Society's Advisory Committee on Cancer Statistics. Canadian Cancer Statistics 2017. Available at: https://www.cancer.ca/ /media/cancer.ca/CW/cancer\%20information/cancer\%20101/Can adian\%20cancer\%20statistics/Canadian-Cancer-Statistics-2017-EN.pdf?la=en. Accessed Jan. 9, 2020

5. Statistics Canada. Canadian Cancer Registry (CCR). [updated: 2020 Jan 28]. Available at: https://www23.statcan.gc.ca/imdb/p2SV.pl?Function=getSurvey\&SDDS=3207. Accessed March 9, 2020.

6. National Cancer Institute: Surveillance, Epidemiology, and End Results Program. Bethesda, MD: SEER Cancer Stat Facts: Kidney and Renal Pelvis Cancer. Available at: https://seer.cancer.gov/statfacts/html/kidrp.html. Accessed Jan. 9, 2020.

7. Canadian Cancer Society's Advisory Committee on Cancer Statistics. Canadian Cancer Statistics 2019. Available at:

https://www.cancer.ca/ /media/cancer.ca/CW/cancer\%20information/cancer\%20101/Can adian\%20cancer\%20statistics/Canadian-Cancer-Statistics-2019-EN.pdf. Accessed Jan. 2, 2020.

8. Statistics Canada: Number and proportion of visible minority population in Canada, 1981-2036. Available at: https://www.statcan.gc.ca/eng/dai/btd/othervisuals/other010. Accessed March 6, 2020.

9. Wong ECL, Breau RH, Mallick R, et al. Renal cell carcinoma in the Canadian Indigenous population. Curr Oncol 2019 Jun;26:e367-71.

10. Atkins MB, Choueiri TK. Epidemiology, pathology and pathogenesis of renal cell carcinoma. UpToDate [serial on the Internet]. Jan 2020 [updated Jan 21, 2020] . Available at: https://www.uptodate.com/contents/epidemiology-pathology-andpathogenesis-of-renal-cellcarcinoma?search=kidney\%20cancer\%20pathology\&source=search_result\&selectedTitle $=1 \sim 150 \&$ usage_type=default\&display_rank=1\%20-\%20H17. Accessed Jan. 9, 2020. 
11. Himmelman JG, Merrimen J, Matheson K, et al. Accuracy of kidney cancer diagnosis and histological subtype within Canadian cancer registry data. Can Urol Assoc J 2017;11:E326-29.

12. Statistics Canada. Canada's rural population since 1851. [February 2012]. Available at: https://www12.statcan.gc.ca/census-recensement/2011/as-sa/98-310-x/98-310x2011003_2-eng.pdf. Accessed Jan. 9, 2020. 


\section{Figures and Tables}

Fig. 1. Consort diagram: CKCis cohort January 1, 2011 to December 31, 2018

Total Prospective Patients: $\mathrm{N}=11016$

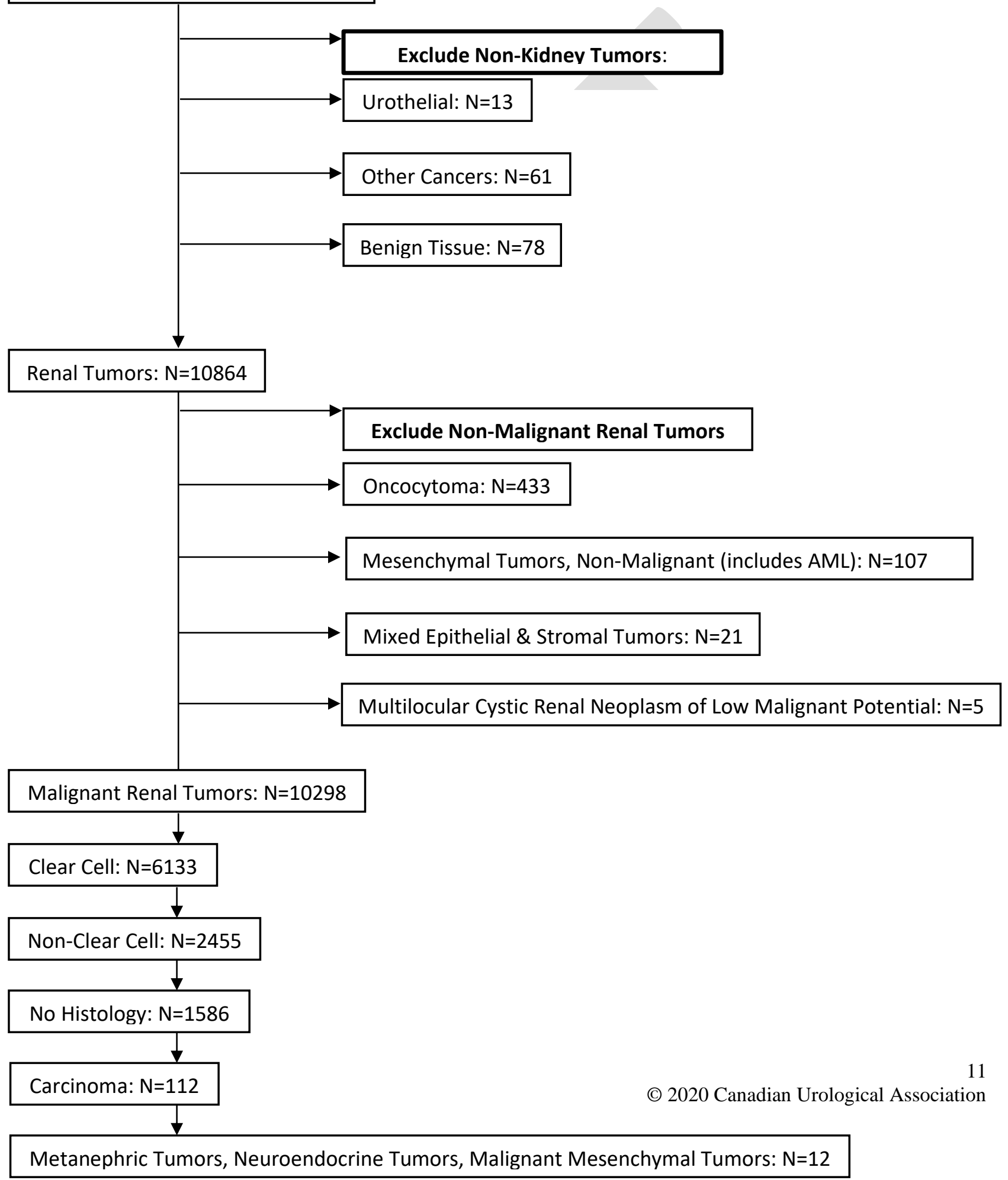


Fig. 2. CKCis Canadian and provincial accrual via forward sortation area geography (FSA) 2011-2018.

(A) Canada

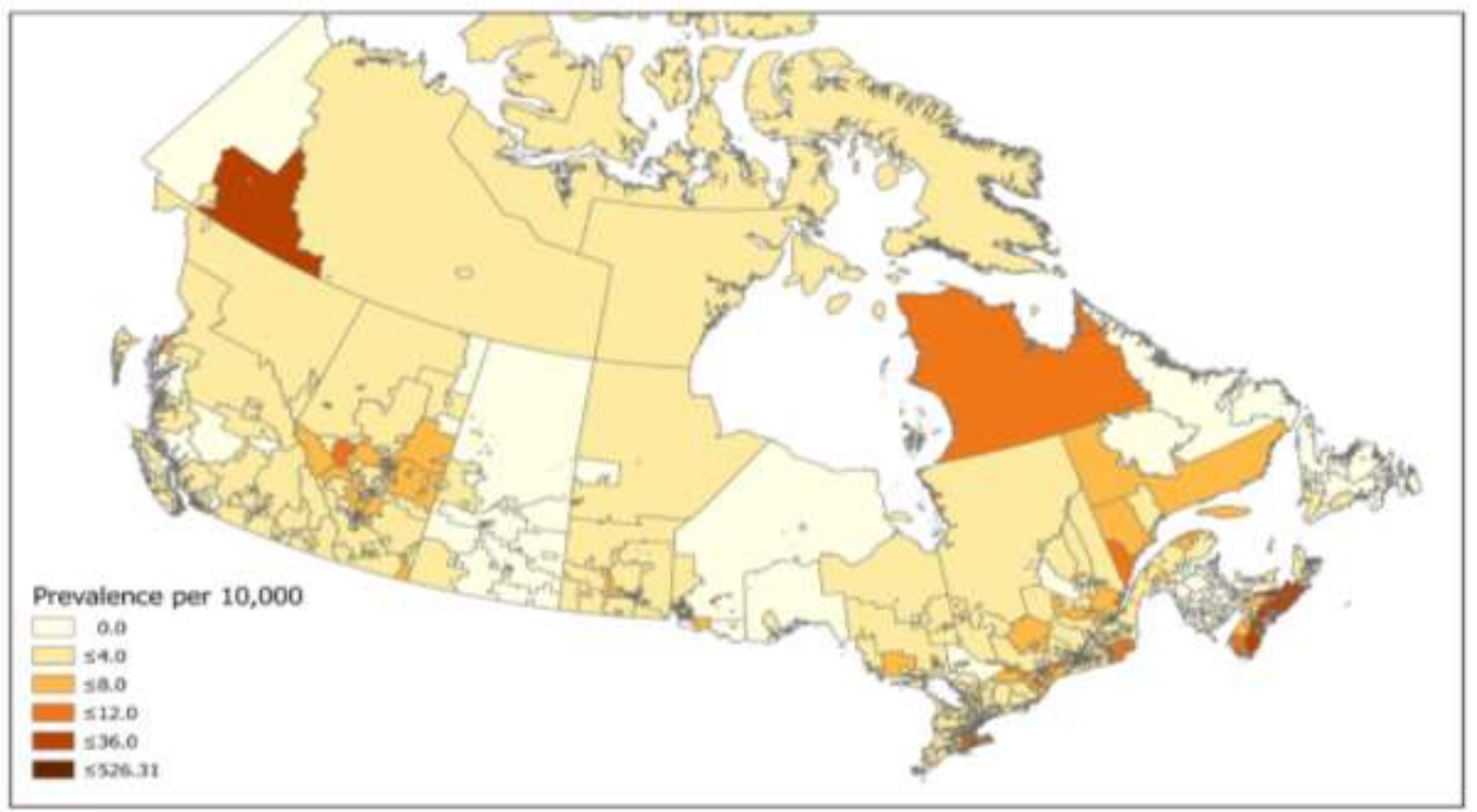

(B) British Columbia

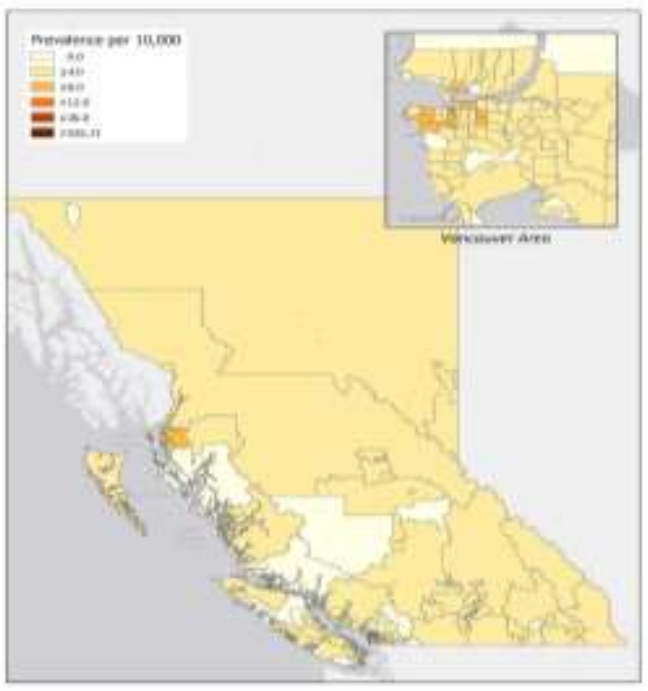

(C) Alberta

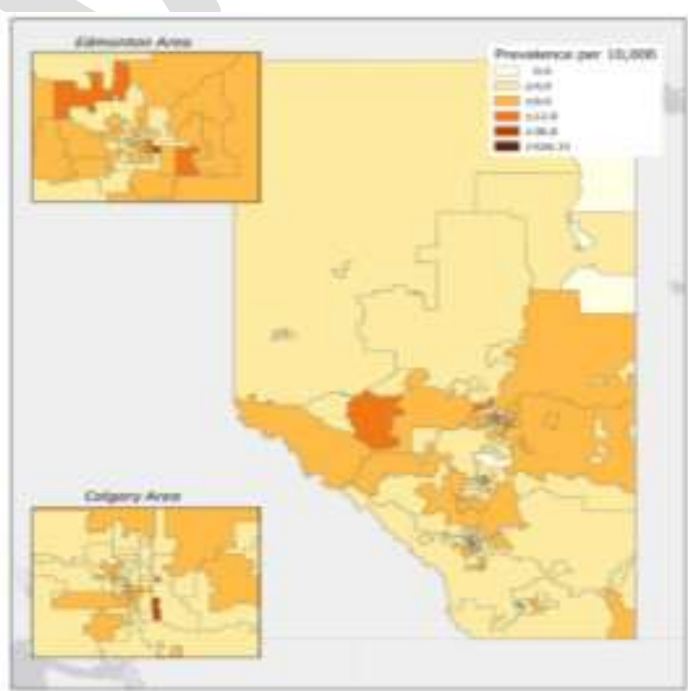


(D) Manitoba

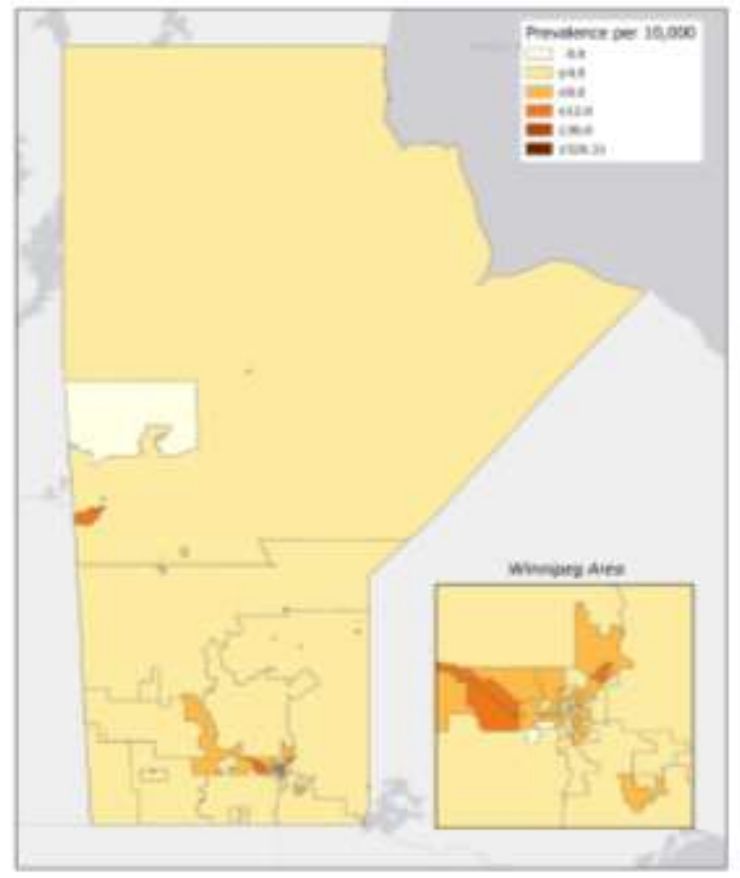

(F) Quebec

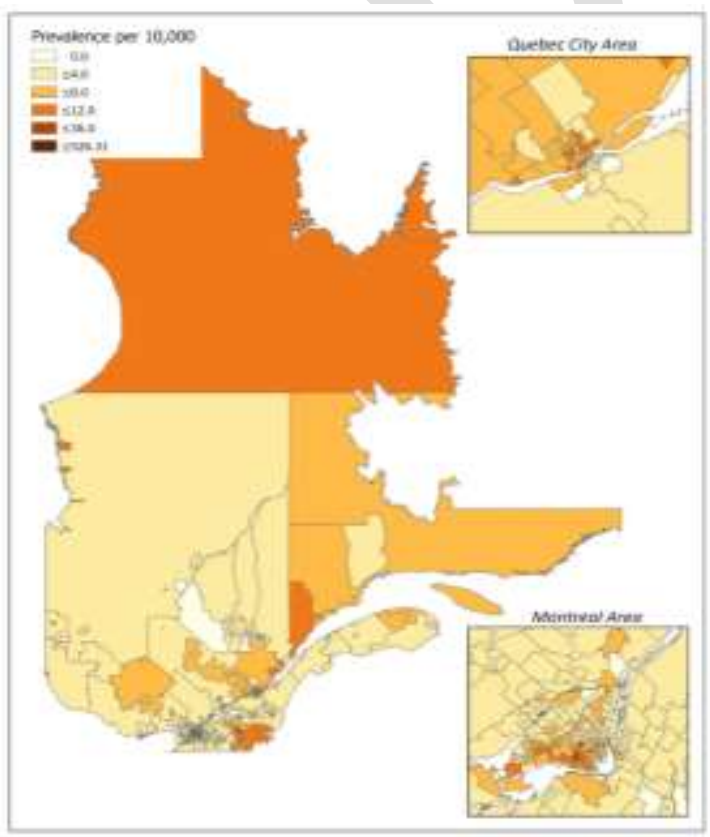

E) Ontario

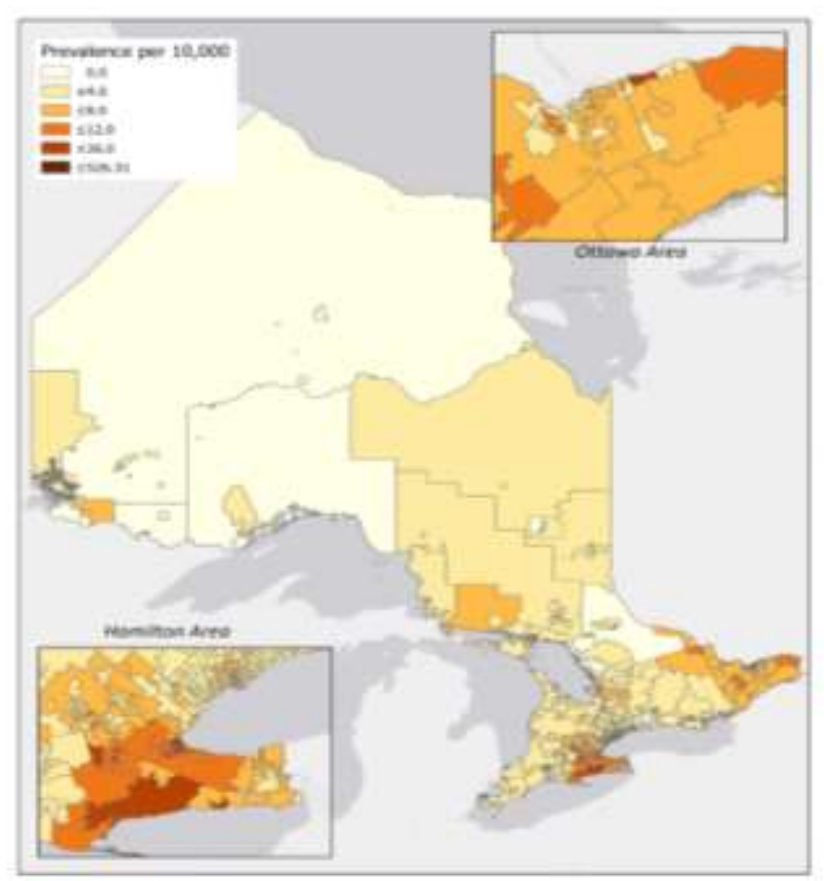

(G) Nova Scotia

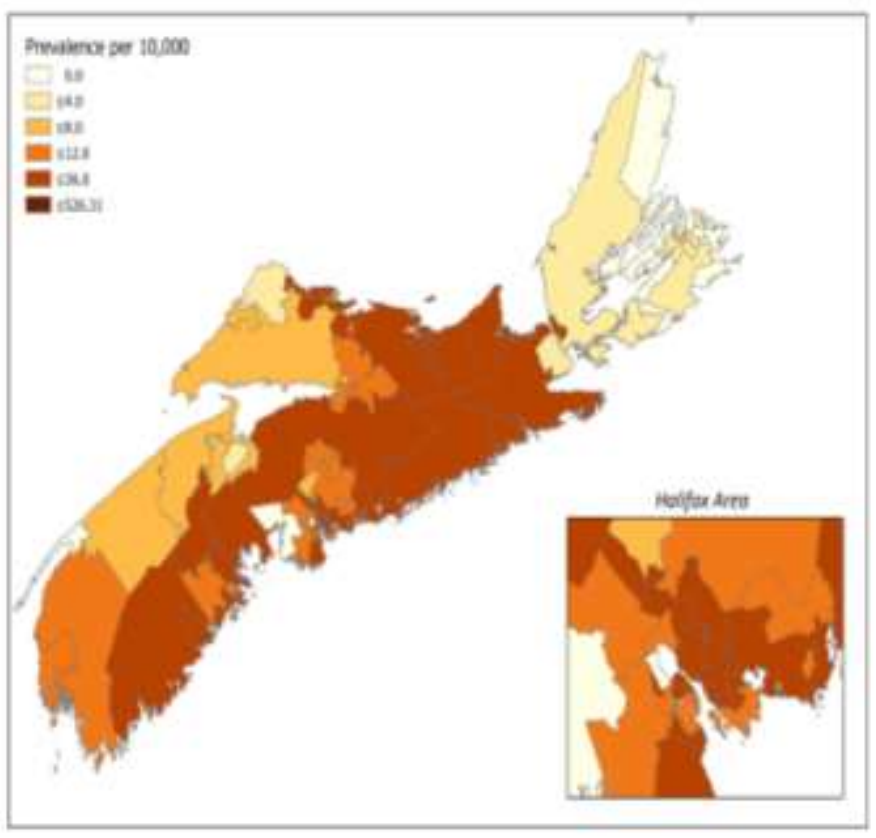




\begin{tabular}{|l|c|c|c|c|c|c|c|}
\hline \multicolumn{7}{|l|}{ Table 1. Baseline demographics of patients 2011-2018 } \\
\hline & Canada $^{*}$ & BC & AB & MB & ON & QC & NS \\
\hline $\mathrm{n}$ & 10298 & 698 & 1392 & 444 & 4121 & 2600 & 978 \\
\hline $\begin{array}{l}\text { Age, median } \\
\text { (yrs) }\end{array}$ & 62.6 & 62.4 & 61.4 & 61.6 & 62.6 & 62.8 & 64.4 \\
\hline Male (\%) & 66.6 & 70.2 & 70.4 & 66.2 & 65.3 & 66.0 & 66.6 \\
\hline Caucasian (\%) & 85.6 & 64.5 & 80.7 & 82.6 & 83.7 & 91.0 & 98.7 \\
\hline $\begin{array}{l}\text { Rural } \\
\text { Residence (\%) }\end{array}$ & 17.0 & 9.7 & 15.0 & 23.9 & 15.1 & 15.7 & 32.0 \\
\hline $\begin{array}{l}\text { De novo } \\
\text { metastatic (\%) }\end{array}$ & 14.6 & 19.9 & 17.2 & 16.7 & 14.7 & 9.4 & 19.1 \\
\hline $\begin{array}{l}\text { Metastatic any } \\
\text { time (\%) }\end{array}$ & 31.1 & 41.1 & 35.6 & 42.1 & 31.2 & 22.8 & 34.4 \\
\hline
\end{tabular}

*Includes 65 patients from Saskatchewan, Newfoundland, PEI, Yukon, Nunavut, and Northwest Territories.

\section{Table 2. 2016 CKCis demographics compared to national RCC Data}

\begin{tabular}{|c|c|c|c|c|}
\hline & CKCis cohort & $\begin{array}{c}\text { National RCC } \\
\text { data }\end{array}$ & 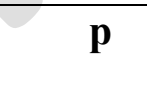 & Data source \\
\hline $\begin{array}{l}\text { Age, median } \\
\text { (years) }\end{array}$ & 63 & 64 & $\mathrm{NA}^{\wedge}$ & $\mathrm{CCR}^{*}, 2016$ \\
\hline Male & $65.5 \%$ & $64.8 \%$ & 0.60 & CCR, 2016 \\
\hline Rural residence & $17.0 \%$ & $18.7 \%$ & 0.12 & CCR, 2016 \\
\hline Race, Caucasian & $86.4 \%$ & $77.7 \%$ & $\mathrm{NA}^{\wedge}$ & $\begin{array}{c}\text { Canadian } \\
\text { census, } 2016\end{array}$ \\
\hline $\begin{array}{l}\text { De novo } \\
\text { metastatic }\end{array}$ & $14.7 \%$ & $16 \%$ & $\mathrm{NA}^{\wedge}$ & $\begin{array}{l}\text { SEER data, } \\
\text { 2009-2015 }\end{array}$ \\
\hline $\begin{array}{l}\text { Clear-cell } \\
\text { histology (in } \\
\text { those with a } \\
\text { cancer diagnosis) }\end{array}$ & $\begin{array}{c}58.6 \% \\
\text { (all patients) } \\
71.4 \% \\
\text { (in only those with } \\
\text { pathology) }\end{array}$ & $59.6 \%$ & 0.46 & CCR, 2016 \\
\hline
\end{tabular}

No formal statistical comparison was performed due to lack of data. ${ }^{*}$ Canadian Cancer Registry, CCR: Canadian Cancer Registry; RCC: renal cell carcinoma; SEER: Surveillance, Epidemiology, and End Results. 


\begin{tabular}{|c|c|c|c|c|c|c|}
\hline & CCR 2016 & CCS 2016 & $\begin{array}{c}\text { Absolute } \\
\text { difference } \\
\text { between } \\
\text { CCR and } \\
\text { CCS } \\
\end{array}$ & CKCis 2016 & $\begin{array}{l}\text { \% patients } \\
\text { captured } \\
\text { vs. CCR }\end{array}$ & $\begin{array}{l}\text { \% patient } \\
\text { captured } \\
\text { Vs. CCS }\end{array}$ \\
\hline Canada & $4395(\operatorname{excl} Q C)$ & $\begin{array}{c}6400 \text { (total) } \\
4750(\text { excl QC) }\end{array}$ & -355 & $\begin{array}{c}1255 \text { (total) } \\
908 \text { (excl QC) }\end{array}$ & $20.7(\mathrm{excl} Q \mathrm{Q})$ & $\begin{array}{c}19.6 \text { (total) } \\
19.1 \text { (excl QC) }\end{array}$ \\
\hline $\mathrm{BC}$ & 690 & 630 & +60 & 80 & 11.6 & 12.7 \\
\hline $\mathrm{AB}$ & 515 & 600 & -85 & 186 & 36.1 & 31.0 \\
\hline MB & 205 & 275 & -70 & 59 & 28.8 & 21.5 \\
\hline ON & 2265 & 2320 & -55 & 467 & 20.6 & 20.1 \\
\hline QC & & 1650 & & 347 & & 21.0 \\
\hline NS & 210 & 250 & -40 & 108 & 51.4 & 43.2 \\
\hline
\end{tabular}

CCR: Canadian Cancer Registry; CCS: Canadian Cancer Society. 


\begin{tabular}{|c|c|c|c|}
\hline \multicolumn{4}{|c|}{ Supplementary Table 1. Canadian Kidney Cancer information system sites } \\
\hline Centre(s) & Location & Uro-oncologist & Medical oncologist \\
\hline University Health Network & Toronto & Antonio Finelli* & Aaron Hansen \\
\hline Capital Health QEII Hospital & Halifax & Ricardo Rendon & Lori Wood* \\
\hline $\begin{array}{l}\text { McGill University Health Centre, } \\
\text { Jewish General Hospital }\end{array}$ & Montréal & Simon Tanguay & François Patenaude \\
\hline $\begin{array}{l}\text { St. Joseph's Healthcare Hamilton, } \\
\text { Juravinski Cancer Centre }\end{array}$ & Hamilton & Anil Kapoor ${ }^{*}$ & Aly-Khan Lalani \\
\hline Tom Baker Cancer Centre & Calgary & Bimal Bhindi & Daniel Heng* \\
\hline Cross Cancer Institute & Edmonton & Adrian Fairey & Naveen Basappa* \\
\hline Vancouver General Hospital & Vancouver & Alan So* & $\begin{array}{c}\text { Christian } \\
\text { Kollmannsberger }\end{array}$ \\
\hline St. Boniface Hospital & Winnipeg & Darrel Drachenberg $^{*}$ & Jeffrey Graham \\
\hline Sunnybrook Hospital & Toronto & Laurence Klotz & Georg Bjarnason $^{*}$ \\
\hline The Ottawa Hospital & Ottawa & $\begin{array}{l}\text { Luke Lavallée* / } \\
\text { Rodney Breau }\end{array}$ & $\begin{array}{l}\text { Neal Reaume/ } \\
\text { Christina Canil }\end{array}$ \\
\hline $\begin{array}{l}\text { Centre hospitalier de l'Université de } \\
\text { Montréal }\end{array}$ & Montréal & Denis Soulières* & Jean-Baptiste Lattouf \\
\hline $\begin{array}{l}\text { Centre hospitalier universitaire de } \\
\text { Québec }\end{array}$ & Québec & Frédéric Pouliot ${ }^{*}$ & Vincent Castonguay \\
\hline London Health Sciences Centre & London & Nicholas Power ${ }^{*}$ & Eric Winquist \\
\hline $\begin{array}{l}\text { Centre hospitalier universitaire de } \\
\text { Sherbrooke }\end{array}$ & Sherbrooke & Patrick Richard* & Michel Pavic \\
\hline
\end{tabular}

*Principal investigator. 


\begin{tabular}{|l|c|c|c|c|c|c|}
\hline $\begin{array}{l}\text { Supplementary Table 2. CKCis incidence compared to Canadian Cancer Society (2015 } \\
\text { and 2017) }\end{array}$ & CCS 2015 & $\begin{array}{c}\text { CKCis } \\
\mathbf{2 0 1 5}\end{array}$ & $\begin{array}{c}\text { \% } \\
\text { patients } \\
\text { captured }\end{array}$ & CCS 2017 & $\begin{array}{c}\text { CKCis } \\
\mathbf{2 0 1 7}\end{array}$ & $\begin{array}{c}\text { \% patients } \\
\text { captured }\end{array}$ \\
\hline Canada & 6200 & 1314 & 21.2 & 6600 & 1234 & 18.7 \\
\hline BC & 550 & 84 & 15.3 & 700 & 107 & 15.3 \\
\hline AB & 580 & 202 & 34.8 & 610 & 113 & 18.5 \\
\hline MB & 240 & 53 & 22.1 & 235 & 38 & 16.2 \\
\hline ON & 2450 & 520 & 21.2 & 2450 & 534 & 21.8 \\
\hline QC & 1580 & 349 & 22.1 & 1710 & 329 & 19.2 \\
\hline NS & 250 & 101 & 40.4 & 260 & 104 & 40.0 \\
\hline
\end{tabular}

CCS: Canadian Cancer Society. 